\title{
Touchless Mechanism to Detect Rhodamine B Concentration in Distilled Water Using Fiber Bundle
}

\author{
Samian (D, A. H. Zaidan (iD, Patricia, R. N. Afifah, and M. Yasin \\ Physics Department, Faculty of Science and Technology, Universitas Airlangga, 60115 Surabaya, Indonesia \\ Correspondence should be addressed to Samian; samian@fst.unair.ac.id
}

Received 5 August 2019; Revised 13 September 2019; Accepted 31 October 2019; Published 27 November 2019

Academic Editor: Wonho Jhe

Copyright @ 2019 Samian et al. This is an open access article distributed under the Creative Commons Attribution License, which permits unrestricted use, distribution, and reproduction in any medium, provided the original work is properly cited.

\begin{abstract}
Detection of rhodamine B concentration in distilled water can be conducted without direct contact between the sensor probe and the sample using fiber bundle as a sensor probe and concave mirror as a sample container. The fiber bundle used is a concentric and a pair bundle probe. The working mechanism of the sensor is based on the displacement sensor and absorption of rhodamine $\mathrm{B}$ on laser light at a wavelength of $543 \mathrm{~nm}$. The concentration of rhodamine B was detected through the valley and the peak voltage resulting from the displacement of the sensor probe to the sample surface. The best performance is shown by a sensor that uses a concentric bundle as a probe with a detection range of $0-20 \mathrm{ppm}$ with a resolution of $0.6 \mathrm{ppm}$.
\end{abstract}

\section{Introduction}

Detection methods of physical, chemical, and biomedical quantities using optical fiber continue to be developed. The Mach-Zender [1] and Michelson interferometer [2-4] techniques have been demonstrated can be used to detect refractive index of liquid. The surface plasmon resonance (SPR) method has been used to detect uric acid concentrations [5] and manganese ion [6]. Side-emitting technique uses a microbend [7] and tapered fiber optic [8] as a sensor probe was successfully applied to detect the refractive index of chlorinated water and uric acid concentration. The method based on optical fiber displacement sensor was successfully used to detect the liquid refractive index [9], concentration of calcium [10], sodium chloride [11], glucose $[12,13]$, rhodamine B [14], and magnesium ion [15]. In all mentioned methods, detection of changes in the refractive index or concentration of the solution is carried out through changes in light intensity due to the displacement of the sensor probe to the reflector. The sample is between the sensor probe and the reflector. The intensity of light is read through the optical detector output voltage. Refractive index or concentration of solution is detected through the peak voltage of the optical detector resulting from the displacement of the sensor probe to the reflector. The reflector is a flat or concave mirror, and the sensor probe used is a fiber bundle [9-12] or fiber coupler [13-15].

Detection of the refractive index or solution concentration using a sensor with the existing method requires to continue maintenance of the sensor probe. This is due to the detection mechanism that requires the sensor probe to be immersed in the sample; what's more, if the remaining sample attached to the sensor probe is difficult to clean. To avoid complicated maintenance of the sensor probe while maintaining the accuracy of the sensor after repeated use, a sensor that can work without direct contact between the sensor probe and the sample is needed. The sensor with touchless working mechanism has been published, which uses fiber coupler as sensor probe to detect concentrations of rhodamine B in distilled water. Detection of changes in the concentration of rhodamine $B$ was carried out through the peak voltage value resulting from the shift of the probe to the sample surface. Samples are placed in concave mirrors that act as sample containers as well as reflectors [16].

As is known, fiber bundle as optical device can be used as liquid concentration sensor. Fiber bundle prices are relatively cheaper and easily acquired in the market than fiber coupler. With these considerations, in this paper, we use fiber bundle to detect the concentration of rhodamine B in distilled water based on displacement sensor without direct 
contact between sensor probe and sample. The sensor design can be used to detect other types of liquids if the liquid can absorb the light source used.

\section{Sensor Work Mechanism}

Sensor design of rhodamine B concentration in distilled water using fiber bundle is shown in Figure 1. Fiber bundle used consists of two types, i.e., concentric and a pair bundle probe. Concave mirrors are used as a reflector as well as a sample container. The volume of sample (solution of rhodamine B) is small, which is almost twice the volume of the concave mirror, so that the form of the solution resembles a convex lens. Therefore, the detected solution must be meniscus (cohesion force is greater than the adhesion force) to not spill from the sample container.

The working mechanism of the sensor can be explained as follows. The light beam from the laser entering the fiber transmitter (TF) is transmitted to the sample. Some of the light will be reflected by the surface of the sample and some will be forwarded to the surface of the concave mirror (passing the sample). Light reflections from the concave mirror will come out bypassing the sample again. Some of the reflecting light from sample and mirror surface will go into the fiber receiver (RF) and proceed to the optical detector. The amount of light intensity that enters the optical detector is read in the form detector's output voltage. Absorption of sample (rhodamine B solution) to the light is the detection principle of sample concentration. Therefore, the light source must have a wavelength that can be absorbed by the sample. In addition, refractive index of the sample must be relatively constant to the changes in sample concentration. Thus, changes in the intensity of light entering the RF are only due to sample absorption, not by refraction or reflection light due to changes in sample concentration. Sensor working mechanism is based on displacement sensor. Shifting the sensor probe away from the sample surface will produce a detector output voltage $(V)$ as a probe displacement function $(d)$. Sensor design using fiber bundle probe and concave mirrors as reflectors will give valley and peak voltage as function of sensor probe displacement to the sample surface. Therefore, detection of rhodamine B concentration in distilled water can be conducted through the valley or the peak voltage obtained.

\section{Experiment}

The experimental setup for detecting rhodamine B concentration using fiber bundle consists of a laser $\mathrm{He}-\mathrm{Ne}$ (with a wavelength of $543 \mathrm{~nm}$ and maximum power of $5 \mathrm{~mW}$ ) as a light source, a silicon photodetector with a digital voltmeter to read the detector output voltage, $X Y Z$ stage with a displacement resolution of $10 \mu \mathrm{m}$ and a range of $25 \mathrm{~mm}$ is used to shift the probe sensor, concave mirrors with curvature radius and diameter of $9 \mathrm{~mm}$ (volume CM $39 \mu \mathrm{l}$ ) as a reflector as well as a sample container, micropipettes (size $10-100 \mu \mathrm{l})$ that were used to measure the volume and place the sample on the container, and fiber bundle. The fiber bundle used in the experiment consists of two types, namely concentric bundle probe made of plastic with a length of $2 \mathrm{~m}$ (structure: a TF of $1 \mathrm{~mm}$ in diameter surrounded by 16 pieces of $0.25 \mathrm{~mm} \mathrm{RF}$ ) and a pair of bundle probes made of plastic ( $2 \mathrm{~m}$ long with TF and RF diameters of $1 \mathrm{~mm}$ each). Rhodamine B solution with distilled water solvent as sample in our experiment has a concentration of $0-20 \mathrm{ppm}$ with variation of 2 ppm.

Before the experiment, the refractive index of each sample concentration was measured using the Abbe refractometer. Experiments began with the displacement characterization of concentric and a pair of bundle probes to concave mirrors. The experiment setup is shown in Figure 2, but without samples. The initial position of the probe is in the middle and almost touches the bottom of the concave mirror. Next, the detector output voltage was recorded for every probe shift of $100 \mu \mathrm{m}$. The next experiment was the detection of rhodamine $\mathrm{B}$ concentration in distilled water using a concentric bundle as a sensor probe with the experimental setup shown in Figure 2. After the sample was in concave mirror (the sample volume was set at $70 \mu \mathrm{l}$, which is almost twice the volume concave mirror for sample not spilt from the sample container), the sensor probe is placed in the middle and is about $0.5 \mathrm{~mm}$ from the highest surface of the sample (as the reference point for shifting the sensor probe). Then, the sensor probe is shifted upward away from the sample surface. Recording the detector output voltage is carried out every sensor probe shifted $100 \mu \mathrm{m}$ away from the sample surface. The experimental procedure was carried out three times for each rhodamine B concentration tested (0-20 ppm with an interval of $2 \mathrm{ppm})$. The next experiment is the use of a pair bundle as a sensor probe. Experimental procedures are the same as experiments using concentric bundles as sensor probes.

\section{Result and Discussion}

The measurement of the refractive index for each solution of rhodamine B used in the experiment has the same value, i.e., 1.333. The absorption of rhodamine $B$ solution to laser light used as source $(543 \mathrm{~nm})$ is 1.03 [16]. Thus, the sample solution of rhodamine $\mathrm{B}$ is in accordance with the proposed sensor working mechanism in term of laser light source absorption and stability of refractive index to the solution concentration. The photograph of samples shaped as convex lenses is shown in Figure 3.

Results' characterization of the shift of concentric and a pair bundle as a sensor probe against concave mirrors is shown in Figure 4. The graph of the relationship between the detector output voltage and the probe displacement produces a valley (valley voltage) and peak (peak voltage). The valley position is at a displacement of $6.6 \mathrm{~mm}$ and $4.2 \mathrm{~mm}$ each for concentric and a pair bundle probe. The peak position is at displacement of $8.8 \mathrm{~mm}$ and $7.1 \mathrm{~mm}$, respectively, for concentric and a pair bundle probe from the reference point. If calculated based on the probe diameter of $4 \mathrm{~mm}$, the reference point is at $0.2 \mathrm{~mm}$ from the base of concave mirror.

The detection results of rhodamine $\mathrm{B}$ concentration in distilled water using concentric and a pair bundle as a sensor 


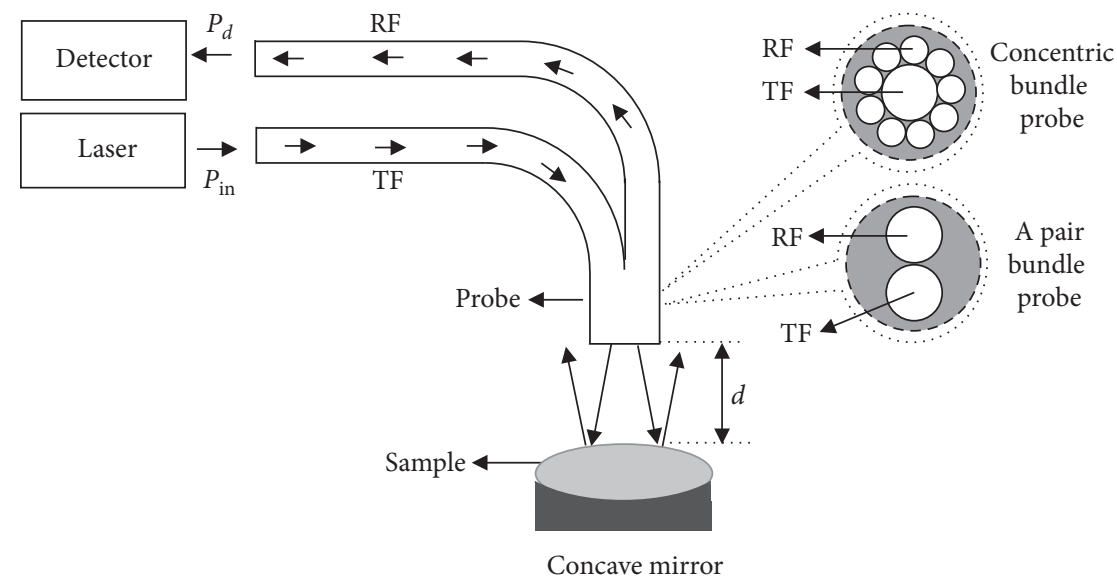

FIGURE 1: Sensor design of rhodamine B concentration in distilled water using fiber bundle and concave mirror as a reflector as well as a sample container.

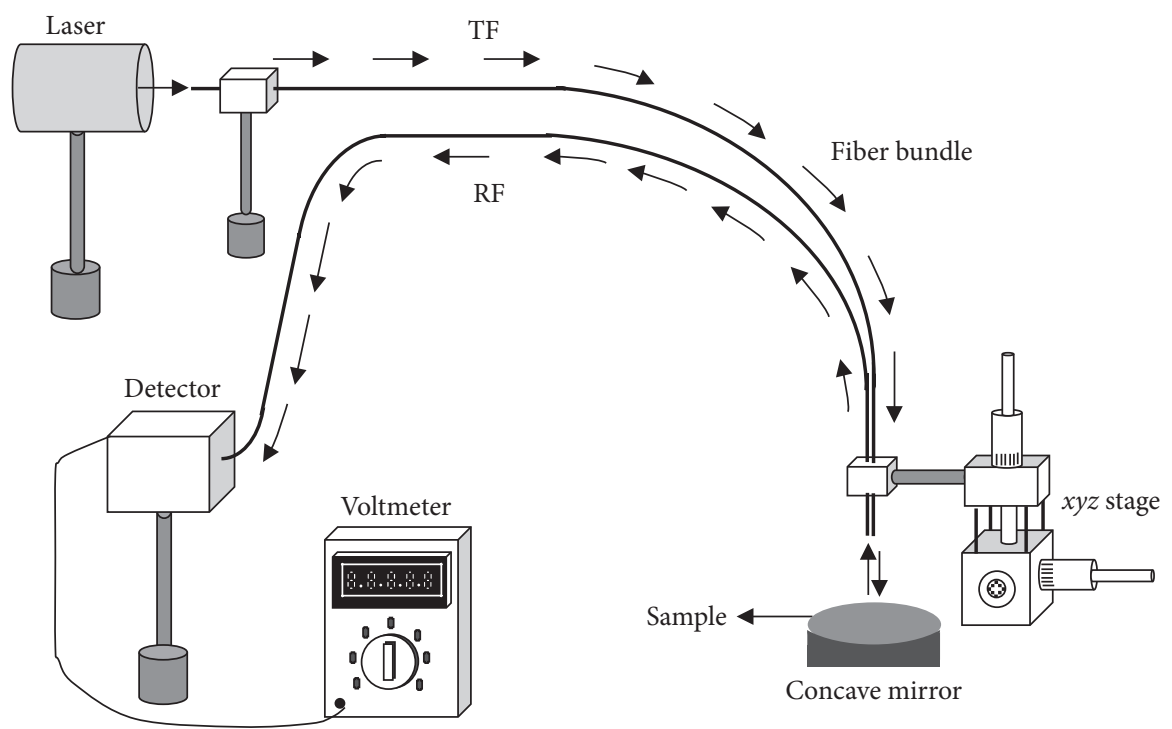

FiguRE 2: Experimental setup of rhodamine B concentration detection using fiber bundle and concave mirror as a reflector and sample container.

probe are shown in Figure 5. The displacement reference point is at $0.5 \mathrm{~mm}$ above the highest surface of the sample. If the sample volume is assumed to be twice the sample container and form like a convex lens, the calculation of the sample height from the base of a concave mirror is $2.4 \mathrm{~mm}$. Thus, the reference point of the sensor probe displacement is $2.9 \mathrm{~mm}$ from the base of a concave mirror. The average position of the valley is at $3.7 \mathrm{~mm}$ and $1.1 \mathrm{~mm}$, respectively, for concentric and a pair bundle probe. Meanwhile, the average position of the peak is at $6.2 \mathrm{~mm}$ and $4.3 \mathrm{~mm}$ for concentric and a pair bundle probes, respectively, from the reference point. The valley position between the graphs in Figures 4 and 5 has a difference of $2.6 \mathrm{~mm}$ and $2.8 \mathrm{~mm}$, respectively, for concentric and a pair bundle probe. For the peak position, there is a difference of $2.9 \mathrm{~mm}$ and $3.1 \mathrm{~mm}$, respectively, for concentric and a pair bundle probe. This difference is caused by the differences in reference points due to the presence of samples in the experiment. In addition to the refraction of light when passing through the sample, the reference point of the sensor probe displacement to the base of the concave mirror (without a sample) of $0.2 \mathrm{~mm}$ also influences the difference in value.

From the data of the detection of rhodamine B level in distilled water in Figure 5, if the observation is conducted through the position of valley voltage ( $V \mathrm{v}$ position) and peak voltage ( $V \mathrm{p}$ position) to the change in concentration, then the results are shown in the graph in Figure 6. The data pattern of the relationship between the average position of $V \mathrm{v}$ and $V \mathrm{p}$ to the change in concentration seems inconsistent or random, except for the data in Figure 6(d). The data in Figure 6(d) also do not look good enough as a parameter for observing changes in concentration. This result is due to for some concentration, the resulting $V \mathrm{p}$ positions have equal value. Thus, it can be concluded that the detection of rhodamine $\mathrm{B}$ concentration cannot be conducted through position of $V \mathrm{v}$ or $V \mathrm{p}$. 


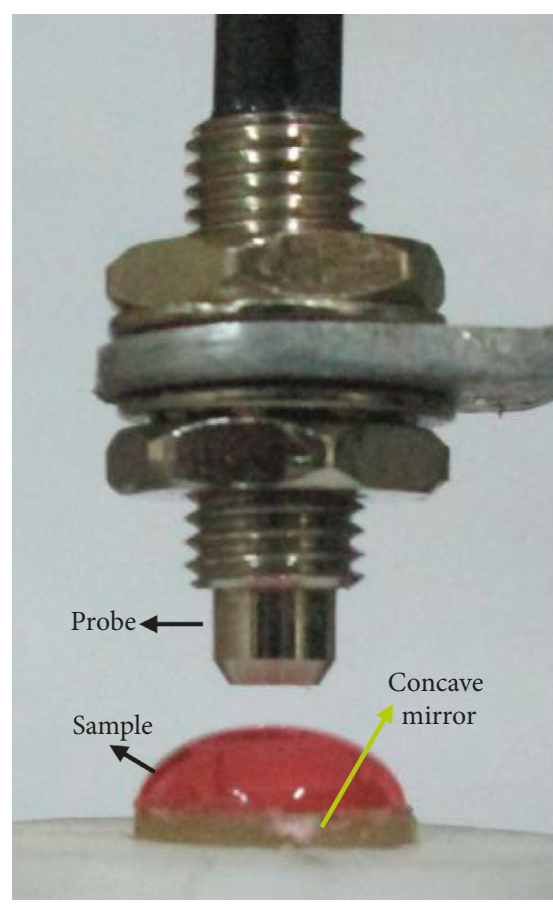

(a)

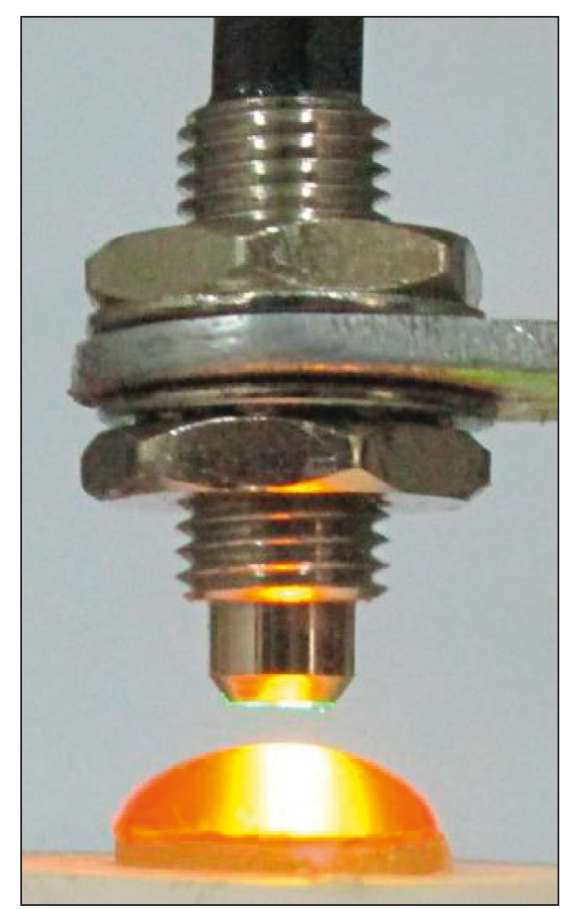

(b)

Figure 3: Photograph of the sample in the container (concave mirror) when (a) no laser light and (b) illuminated by laser light.

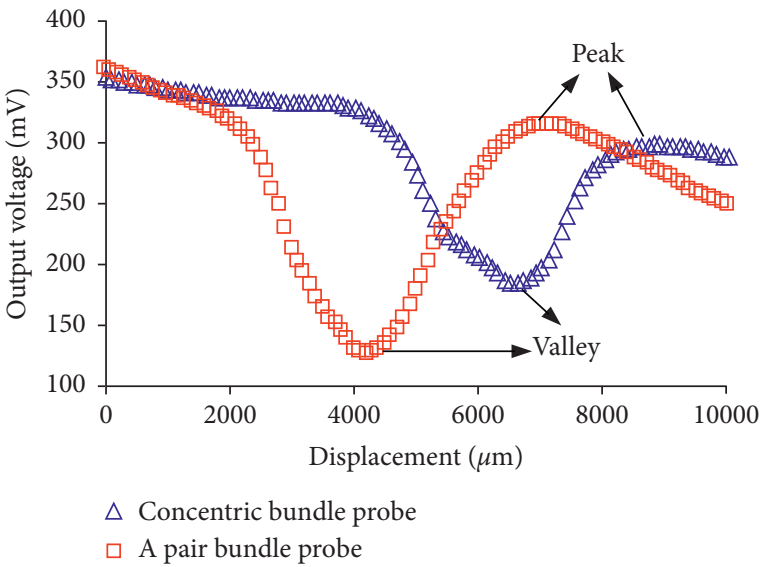

FIGURE 4: Graph of characterization of sensor probes displacement against concave mirrors.

If the detection of rhodamine $\mathrm{B}$ concentration in distilled water is carried out through the valley voltage $(\mathrm{Vv})$ and peak voltage $(V p)$, the results are shown in Figure 7. The data in Figure 7 show that the relationship between $V \mathrm{v}$ and $V \mathrm{p}$ is linear to rhodamine $\mathrm{B}$ concentration with linearity more than $99 \%$. Thus, the concentration of rhodamine $\mathrm{B}$ can be detected through $V \mathrm{v}$ or $V \mathrm{p}$ resulting from the sensor probe displacement to the sample surface. Sensor range of the tested rhodamine $B$ concentration of $0-20 \mathrm{ppm}$ is also a sensor working area (linear region). The linear graph slope value in Figure 7 shows the sensor sensitivity value. The repetition of experiments for the detection of rhodamine B levels was carried out three times, resulting in the largest reduction error in the valley voltage $(\Delta V \mathrm{v})$ and peak voltage $(\Delta V \mathrm{p})$ with the same value of $1.5 \mathrm{mV}$. This value was obtained for both sensors using concentric and a pair bundle as a probe. From the measurement error and sensor sensitivity value, the sensor resolution value can be calculated. Sensor resolution for the use of concentric bundle is $0.6 \mathrm{ppm}$ both for observation through $V \mathrm{v}$ and $V \mathrm{p}$. For the use of a pair bundle, the resulting sensor resolution is $1.1 \mathrm{ppm}$ and $0.7 \mathrm{ppm}$, respectively, for observation via $\mathrm{Vv}$ and $V \mathrm{p}$.

Overall, the performance of rhodamine B concentration sensor using concentric and a pair bundle probes is shown through the characteristics in Table 1. Based on sensor sensitivity and resolution, it is known that sensor performance using concentric bundle probe is better than sensor using a pair bundle probe. Detection of rhodamine $\mathrm{B}$ concentration using concentric bundle as a sensor probe through the valley voltage value is slightly better than the observation through peak voltage. This can be seen from the sensitivity value of the sensor produced. However, both concentric and a pair bundle can be used as a sensor probe to detect rhodamine $\mathrm{B}$ concentration in distilled water.

The $0.6 \mathrm{ppm}$ sensor resolution that is generated using a concentric bundle probe is not better than the results of the previous study of $0.02 \mathrm{ppm}$ [14], but the proposed sensor has the advantage that the detection mechanism is carried out without contact between the sensor probe and the sample. With this mechanism, sensor accuracy can be maintained for longer time and sensor maintenance can be done easier with lower cost. The resulting sensor 


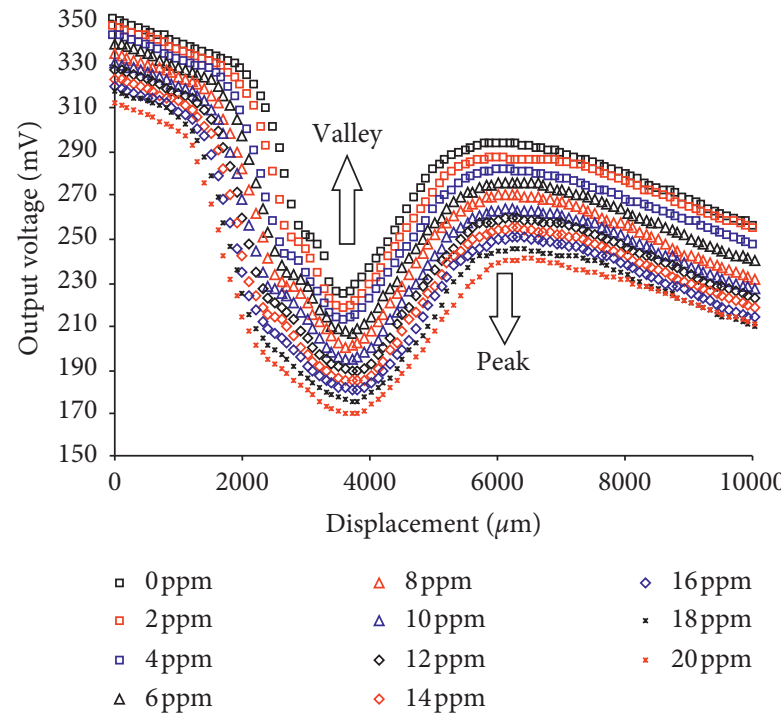

(a)

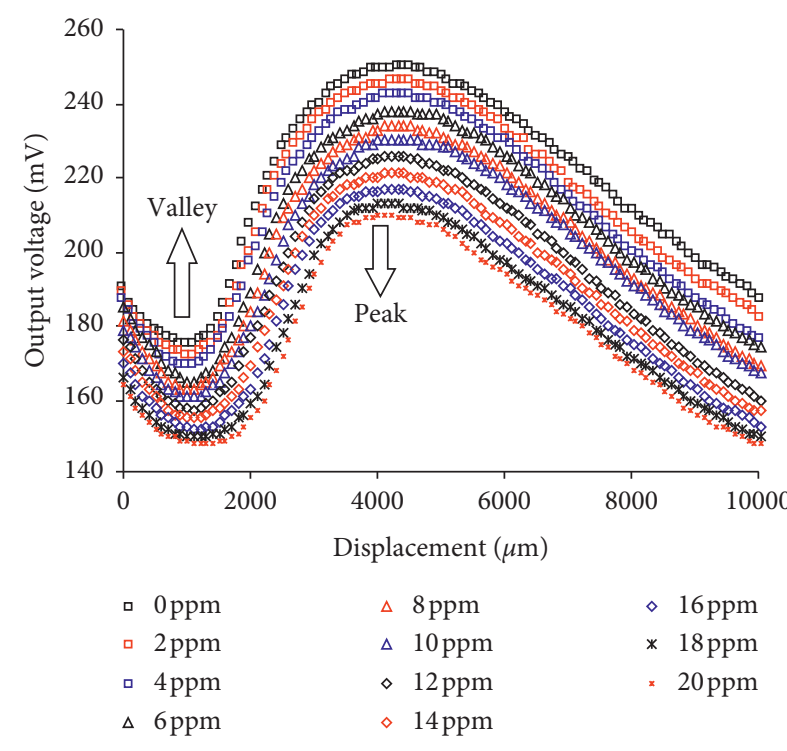

(b)

Figure 5: The curve of output voltage against displacement of (a) concentric bundle probe and (b) a pair bundle probe for rhodamine B solution with different concentrations.

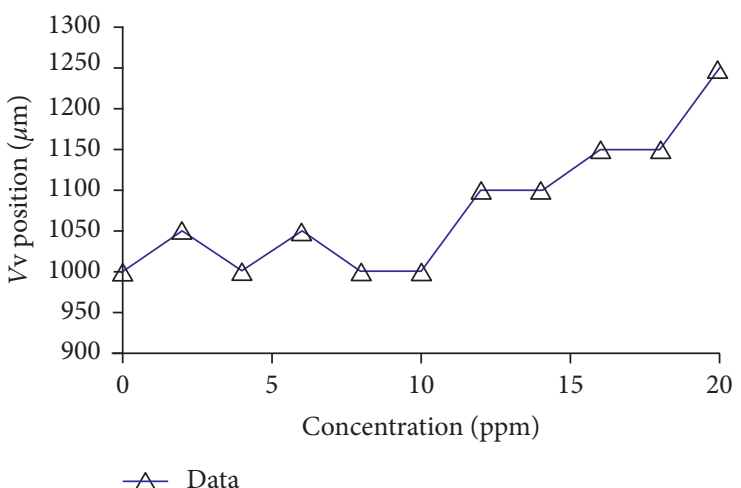

(a)

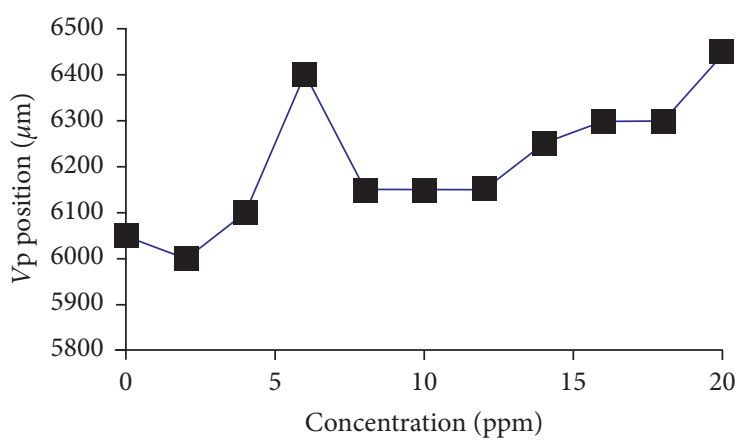

Data

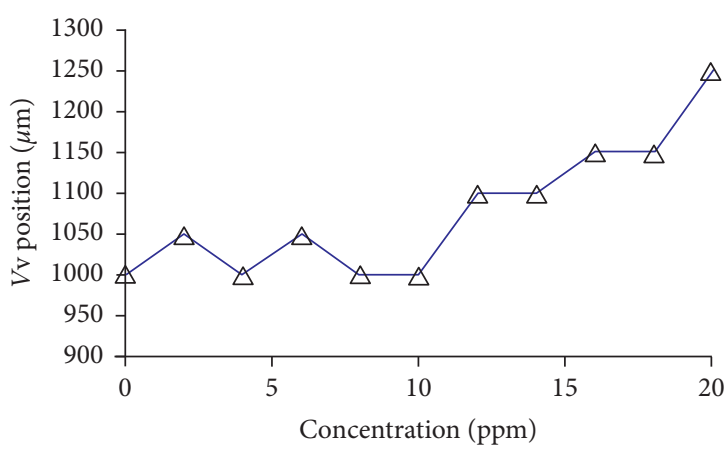

$\triangle$ Data

(b)

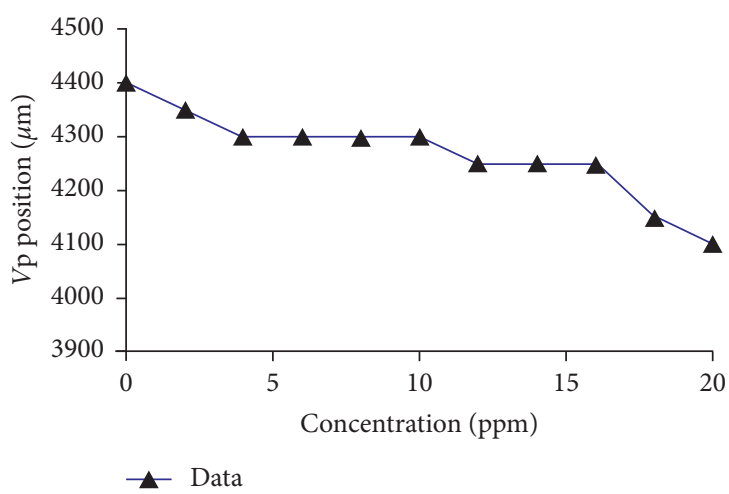

(d)

(c)

FIGURE 6: Graph of the relation between rhodamine B concentration and position of $V v$ for (a) concentric and (b) a pair bundle probe. Also, relation between rhodamine $B$ concentration and position of $V \mathrm{p}$ for (c) concentric use and (d) a pair bundle probe.

resolution is also slightly lower compared to the use of fiber coupler $0.3 \mathrm{ppm}$ [16]. Nevertheless, the sensors that we propose can be used as a choice in building liquid concentration sensors because the cost of manufacturing is relatively cheaper compared to the use of fiber coupler. 


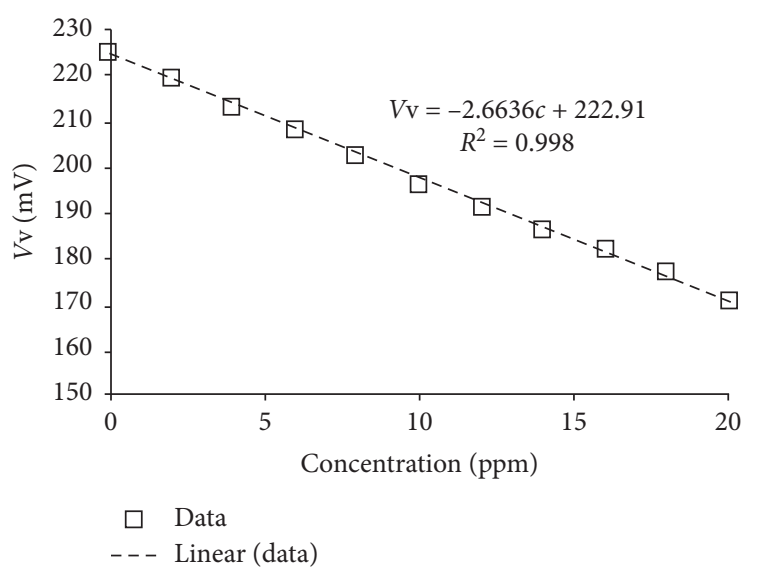

(a)

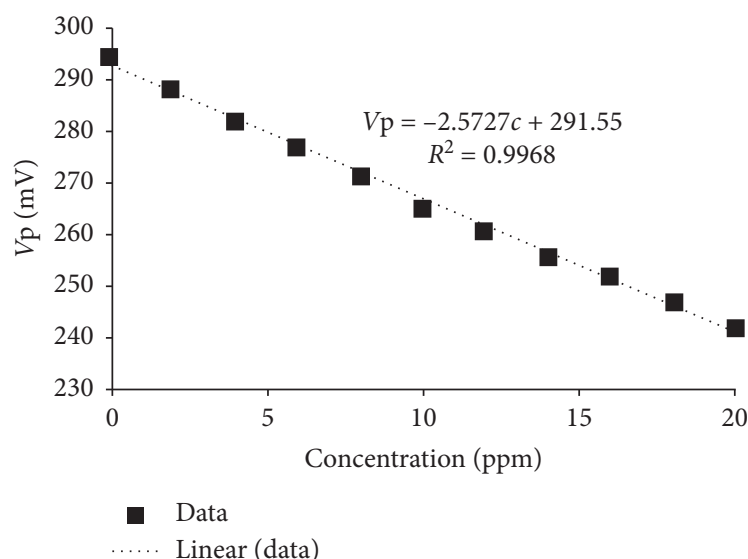

(c)

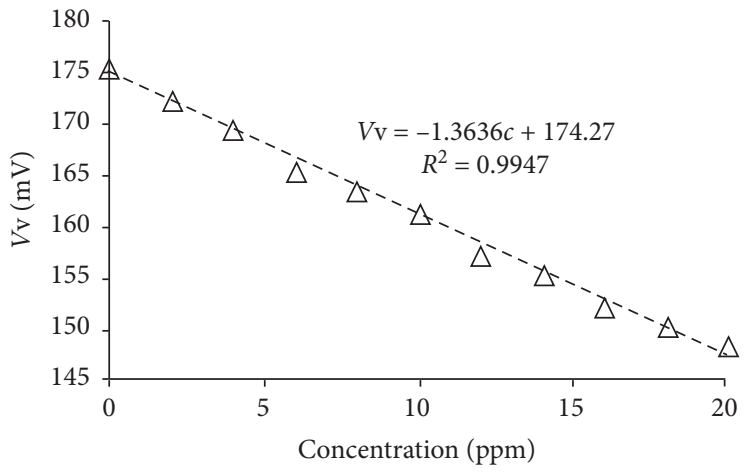

$\triangle$ Data

-- Linear (data)

(b)

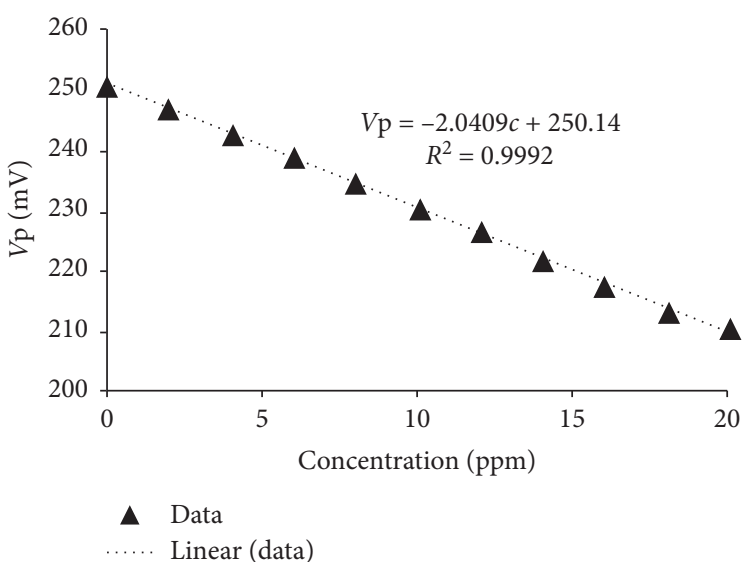

(d)

Figure 7: Graph of relation between rhodamine B concentration and value of $V_{v}$ for (a) concentric use and (b) a pair bundle probe. Also, relation between rhodamine $\mathrm{B}$ concentration and value of $V \mathrm{p}$ for $(\mathrm{c})$ concentric use and (d) a pair bundle probe.

TABLE 1: Characteristics of rhodamine B concentration sensor using concentric and a pair bundle probes.

\begin{tabular}{|c|c|c|c|c|}
\hline \multirow{3}{*}{ Parameters } & \multicolumn{4}{|c|}{ Value } \\
\hline & \multicolumn{2}{|c|}{ Concentric bundle probe } & \multicolumn{2}{|c|}{ A pair bundle probe } \\
\hline & Valley & Peak & Valley & Peak \\
\hline Sensor range (ppm) & $0-20$ & $0-20$ & $0-20$ & $0-20$ \\
\hline Linear region $(\mathrm{ppm})$ & $0-20$ & $0-20$ & $0-20$ & $0-20$ \\
\hline Linearity (\%) & 99.9 & 99.8 & 99.7 & 99.9 \\
\hline Sensitivity (mV/ppm) & 2.66 & 2.57 & 1.36 & 2.04 \\
\hline Resolution (ppm) & 0.6 & 0.6 & 1.1 & 0.7 \\
\hline
\end{tabular}

Sensor resolution can be enhanced using concave mirrors that have a greater focal length, so that the sample volume is larger. A large sample volume will enlarge the optical trajectory. As the working mechanism of the sensor uses the principle of absorption, the magnitude of the optical trajectory will increase the absorption of the sample to the light passing through it. Thus, the sensitivity and sensor resolution will be enhanced.

\section{Conclusion}

Detection of rhodamine concentration in distilled water can be conducted using a concentric or a pair bundle as a sensor probe with concave mirrors as a sample container. The working mechanism of sensor is based on displacement sensor and absorption principle of rhodamine B to green light (wavelength of $543 \mathrm{~nm}$ ). Detection is conducted without direct contact between the sensor probe and the sample and the small sample volume $(70 \mu \mathrm{l})$. The concentration of rhodamine $\mathrm{B}$ was detected through the valley and the peak voltage value resulting from the displacement of the sensor probe to the sample surface. The best characteristics are obtained from sensor using concentric bundle as a sensor probe with a detection range of $0-20 \mathrm{ppm}$ and a resolution of $0.6 \mathrm{ppm}$. 


\section{Data Availability}

The data used to support the findings of this study have not been made available because of commercial sensitivity.

\section{Conflicts of Interest}

The authors declare that they have no conflicts of interest.

\section{Acknowledgments}

The authors thank Universitas Airlangga that supports this work through "Riset Mandat" grant no. 1923/UN3.1.8/LT/ 2018.

\section{References}

[1] R. Bernini and A. Cusano, "Generalized Mach-Zehnder interferometers for sensing applications," Sensors and Actuators B: Chemical, vol. 100, no. 1-2, pp. 72-74, 2004.

[2] J. Zhou, Y. Wang, C. Liao et al., "Intensity modulated refractive index sensor based on optical fiber Michelson interferometer," Sensors and Actuators B: Chemical, vol. 208, pp. 315-319, 2015.

[3] Z. Li, Y. Wang, C. Liao et al., "Temperature-insensitive refractive index sensor based on in-fiber Michelson interferometer," Sensors and Actuators B: Chemical, vol. 199, pp. 31-35, 2014.

[4] Q. Rong, X. Qiao, Y. Du et al., "In-fiber quasi-Michelson interferometer with a core-cladding-mode fiber end-face mirror," Applied Optics, vol. 52, no. 7, pp. 1441-1447, 2013.

[5] R. Kant, R. Tabassum, and B. D. Gupta, "Fiber optic SPRbased uric acid biosensor using uricase entrapped polyacrylamide gel," IEEE Photonics Technology Letters, vol. 28, no. 19, pp. 2050-2053, 2016.

[6] R. Tabassum and B. D. Gupta, "Fiber optic manganese ions sensor using SPR and nanocomposite of $\mathrm{ZnO}$-polypyrrole," Sensors and Actuators B: Chemical, vol. 220, pp. 903-909, 2015.

[7] N. A. George, A. M. Paul, and M. S. Saranya, "Microbend fiber optic detection of continuously varying refractive index of chlorinated water," Optik, vol. 125, no. 1, pp. 301-303, 2014.

[8] H. Rafis, N. Irawati, H. A. Rafaie, H. Ahmad, S. W. Harun, and R. M. Nor, "Detection of different concentrations of uric acid using tapered silica optical sensor coated with zinc oxide (ZnO)," Jurnal Teknologi, vol. 74, no. 8, pp. 55-58, 2015.

[9] G. Govindan, S. G. Raj, and D. Sastikumar, "Measurement of refractive index of liquids using fiber optic displacement sensors," Journal of American Science, vol. 5, no. 2, pp. 13-17, 2009.

[10] M. Yasin, S. Soelistiono, Y. G. Yhun Yhuwana et al., "Intensity based optical fiber sensors for calcium detection," Journal of Optoelectronics and Advanced Materials-Rapid Communications, vol. 9, no. 9-10, pp. 1185-1189, 2015.

[11] H. A. Rahman, S. W. Harun, M. Yasin, and H. Ahmad, "Fiberoptic salinity sensor using fiber-optic displacement measurement with flat and concave mirror," IEEE Journal of Selected Topics in Quantum Electronics, vol. 18, no. 5, pp. 1529-1533, 2012.

[12] S. Binu, V. P. M. Pillai, V. Pradeepkumar, B. B. Padhy, C. S. Joseph, and N. Chandrasekaran, "Fibre optic glucose sensor," Materials Science and Engineering: C, vol. 29, no. 1, pp. 183-186, 2009.
[13] M. Yasin, Samian, and F. N. Aini, "Fiber optic coupler displacement sensor for detection of glucose concentration in distilled water," Journal of Optoelectronics and Advanced Materials-Rapid Communications, vol. 10, no. 5-6, pp. 347350, 2016.

[14] Samian, A. H. Zaidan, and M. Yasin, "Detection of rhodamine B levels in distilled water based on displacement sensor using fiber coupler and concave mirror," Journal of Optoelectronics and Advanced Materials, vol. 18, no. 11-12, pp. 988-992, 2016.

[15] M. Yasin, Samian, and M. Khasanah, "Detection of magnesium ion concentration using fiber coupler based displacement sensor with concave mirror target," Optik, vol. 158, pp. 37-43, 2018.

[16] Samian, A. H. Zaidan, M. P. Anggraeni, M. Yasin, and Supadi, "Non-touch detection of rhodamine B concentration in distilled water using fiber coupler based on displacement sensor," Microwave and Optical Technology Letters, vol. 61, no. 1, pp. 223-228, 2019. 

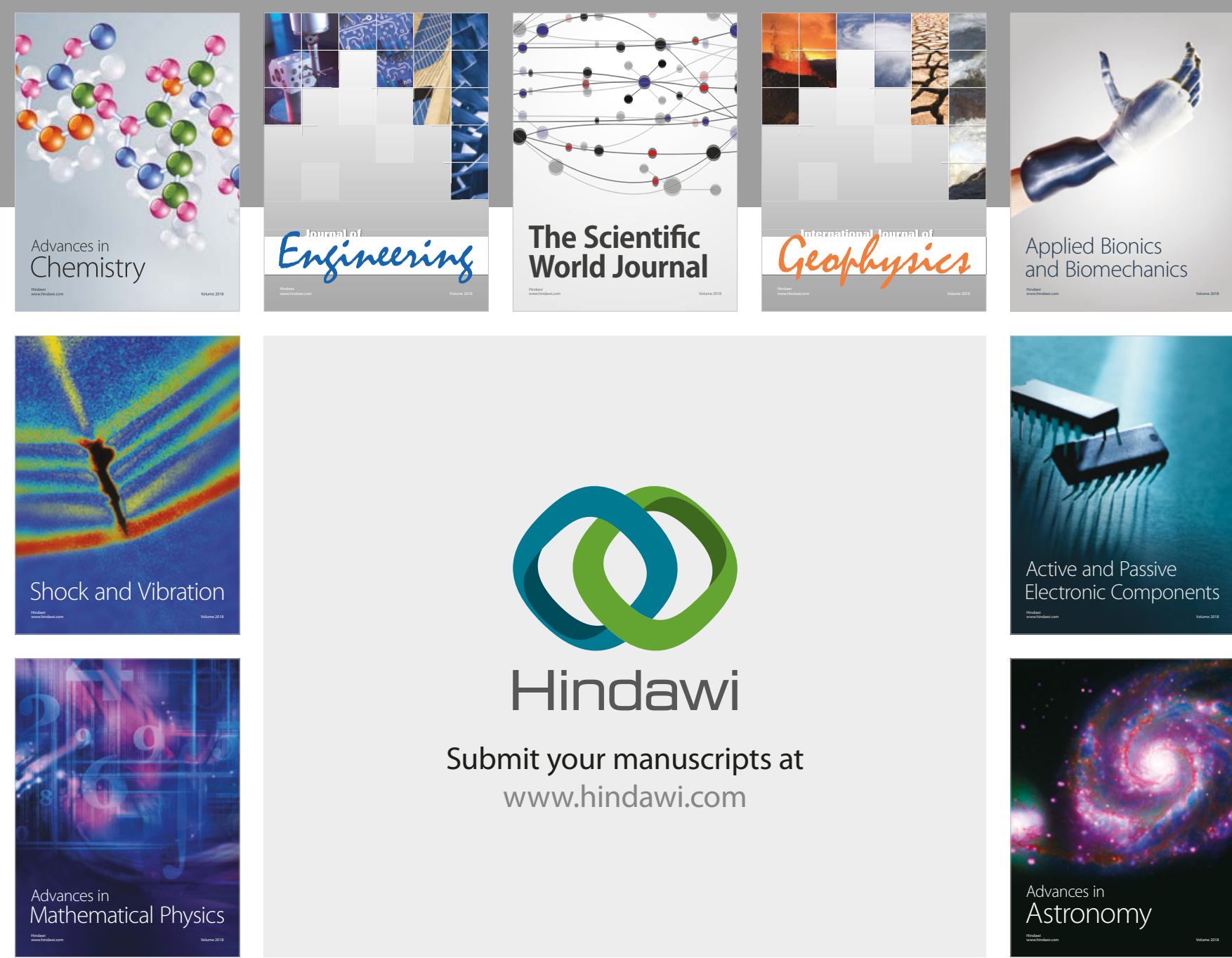

Submit your manuscripts at

www.hindawi.com

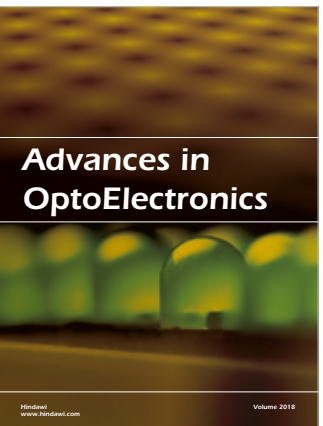

\section{Rotcting Machinery}
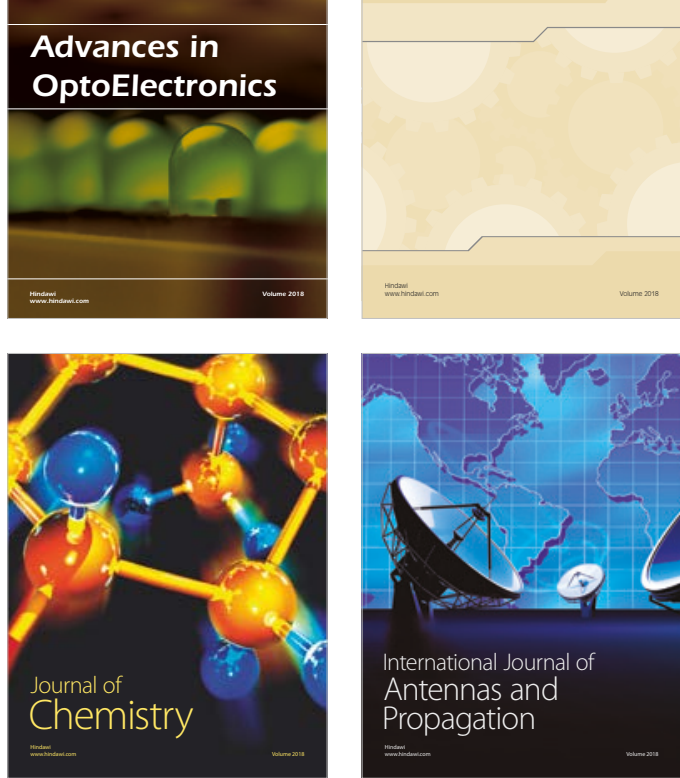

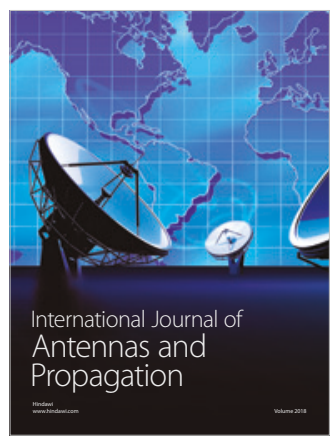

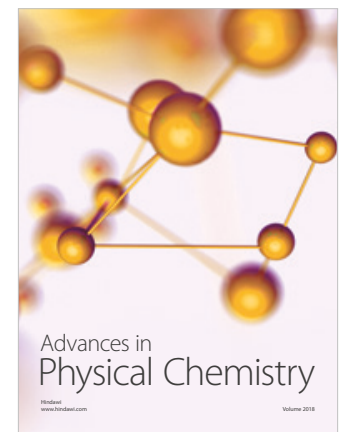

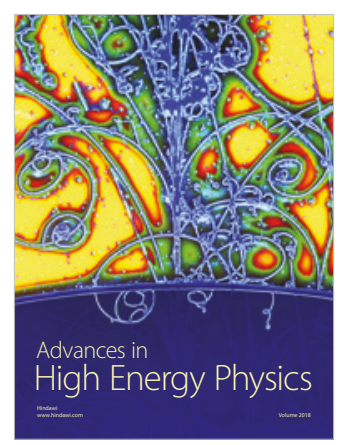

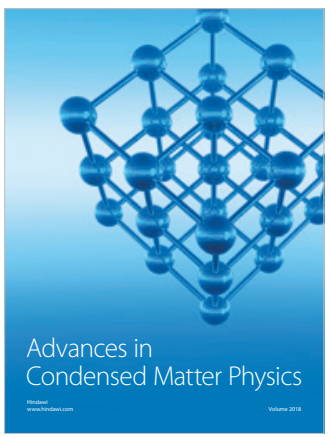

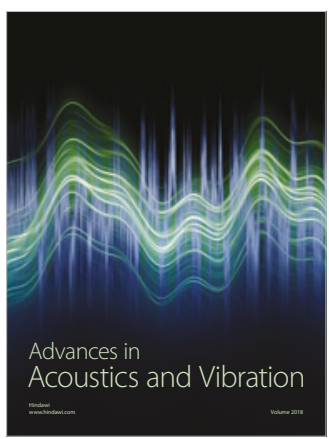

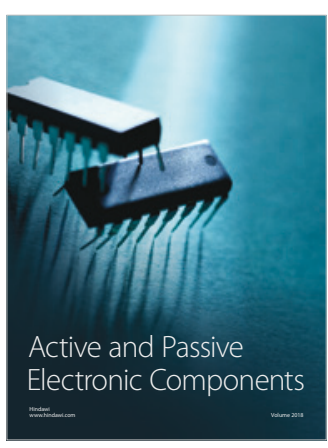
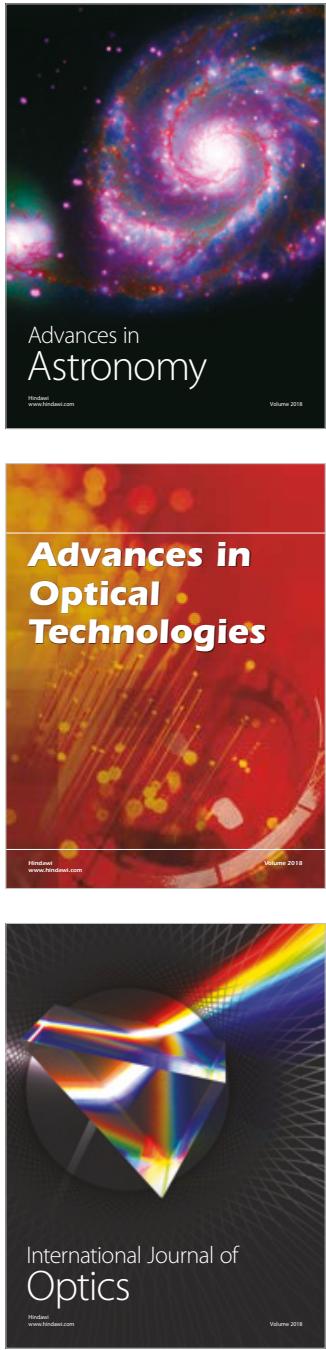